\title{
Stereoselective construction of the pyrrolizidine bridgehead stereochemistry by the adjacent hydroxyl group in the synthesis of (+)-heliotridine and (-)-retronecine
}

\author{
Jie-Ming Huang, Sea-Chuan Hong, Kun-Liang Wu and Yeun-Min Tsai* \\ Department of Chemistry, National Taiwan University, Taipei, 106, Taiwan, ROC \\ Received 30 January 2004; revised 17 February 2004; accepted 19 February 2004
}

\begin{abstract}
Formal total synthesis of (+)-heliotridine (4) and total synthesis of (-)-retronecine (5) were accomplished by using (S)-3acetoxysuccinimide (6) as the common starting material. The stereogenic center of $\mathbf{6}$ ended up as C-1 in both alkaloids. The chiral centers at C-7a of the alkaloids were stereoselectively constructed through the help of the adjacent functionality at C-1. The B-rings of the alkaloids were formed through $\alpha$-sulfonyl radical cyclizations.
\end{abstract}

(c) 2004 Elsevier Ltd. All rights reserved.

Pyrrolizidine alkaloids are an important class of compounds that continue to attract the attention of synthetic chemists. ${ }^{1,2}$ Several years ago (Scheme 1), we developed an $\alpha$-sulfonyl free radical cyclization approach for the synthesis of supinidine (3), the most simple unsaturated necine base of the pyrrolizidine alkaloids. ${ }^{3,4}$ In this letter, we wish to report the successful stereoselective synthesis of (+)-heliotridine (4) and (-)-retronecine (5) using similar methodology.
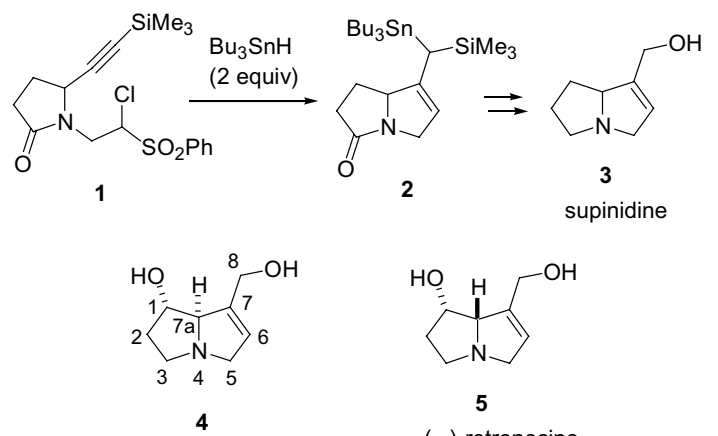

(+)-heliotridine

(-)-retronecine

Scheme 1.

Keywords: Pyrrolizidines; (+)-Heliotridine; (-)-Retronecine; Total synthesis; Radical cyclization.

* Corresponding author. Tel.: +886-2-23690152x117; fax: +886-2-23636359; e-mail: ymtsai@ntu.edu.tw
Our synthetic approach started from enantiopure imide 6 (Scheme 2), which can be synthesized easily from (-)malic acid. ${ }^{5,6}$ The pre-existing stereogenic center in imide 6 can be transformed into $\mathrm{C}-1$ of (+)-heliotridine (4) and (-)-retronecine (5). Relying on the oxygen functionality of this stereogenic center, we planned to construct the adjacent chiral center in a controlled fashion.

As shown in Scheme 3, imide 6 was coupled with 2-phenylthioethanol using triphenylphosphine and diisopropyl azodicarboxylate (DIAD). ${ }^{7}$ The resulting imide acetate product was then stirred in methanol with the presence of catalytic amount of camphor sulfonic acid (CSA) to afford imide alcohol 9 in $78 \%$ yield. Treatment of imide alcohol 9 with excess lithium trimethylsilylacetylide ( 3 equiv) gave a mixture of diastereomeric lactam diol 10a. This diol mixture was directly reduced with triethylsilane and borontrifluoride etherate

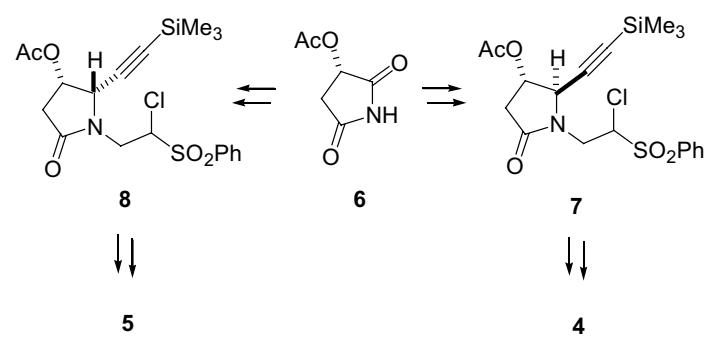

Scheme 2. 

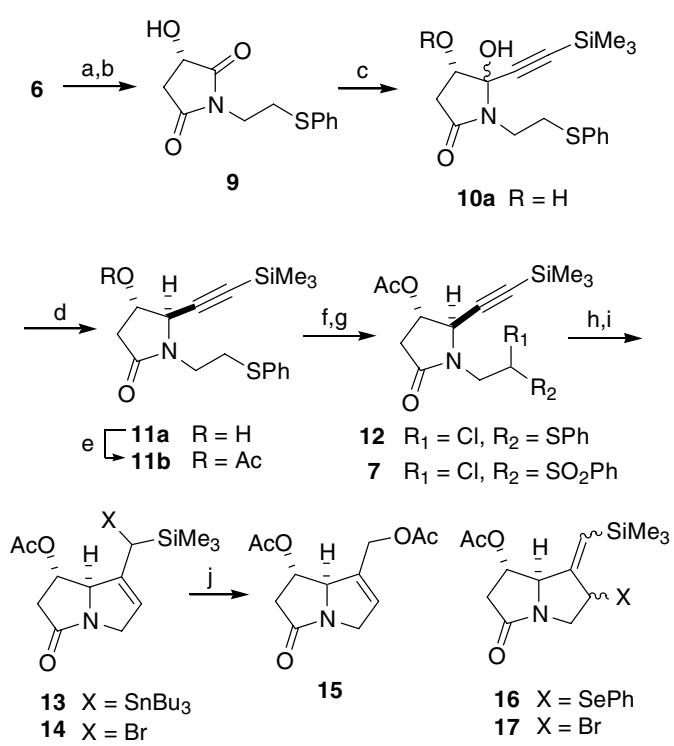

Scheme 3. Reagents and conditions: (a) $\mathrm{Ph}_{3} \mathrm{P}, \mathrm{DIAD}, \mathrm{PhS}\left(\mathrm{CH}_{2}\right)_{2} \mathrm{OH}$; (b) $\mathrm{MeOH}, \mathrm{CSA}$ (cat.), $78 \%$; (c) $\mathrm{LiCCSiMe}_{3}$ (3 equiv), $-78^{\circ} \mathrm{C}$; (d) $\mathrm{Et}_{3} \mathrm{SiH}, \mathrm{BF}_{3} \cdot \mathrm{OEt}_{2}, \mathrm{CH}_{2} \mathrm{Cl}_{2},-78$ to $0^{\circ} \mathrm{C}, 96 \%$ from 9; (e) $\mathrm{Ac}_{2} \mathrm{O}$, 4-DMAP (cat.), $\mathrm{Et}_{3} \mathrm{~N}, \mathrm{CH}_{2} \mathrm{Cl}_{2}, 92 \%$; (f) $\mathrm{NCS}, \mathrm{CCl}_{4}$; (g) MCPBA, $\mathrm{CH}_{2} \mathrm{Cl}_{2}, 86 \%$; (h) $\mathrm{Bu}_{3} \mathrm{SnH}$ (3 equiv), AIBN (0.1 equiv), $\mathrm{C}_{6} \mathrm{H}_{6}, 80{ }^{\circ} \mathrm{C}$, $81 \%$; (i) $\mathrm{PhSeBr}$ (2 equiv), $\mathrm{LiBr}$ (8 equiv), $\mathrm{CH}_{3} \mathrm{CN},-40{ }^{\circ} \mathrm{C}$ to $\mathrm{rt}, 90 \%$; (j) $\mathrm{KOAc}$ (2.5 equiv), 18-crown-6 (0.1 equiv), $\mathrm{H}_{2} \mathrm{O}$ (1.2 equiv), $\mathrm{CH}_{3} \mathrm{CN}$, $58 \%$.

to give lactam 11a as a single isomer (96\% yield from 9$){ }^{8}$ The stereocontrol of the reduction step was excellent.

In fact we surveyed several blocking groups on the C-4 hydroxyl group of lactam diol 10a to examine the stereoselectivity of the reduction (Table 1). In the case with triethylsilane and borontrifluoride etherate (entries 1-4), the reduction of the unprotected lactam diol 10a (entry 1) gave the highest yield with excellent trans-stereoselectivity. Even when we used a bulky $t$-butyldiphenylsilyl group to protect the C-4 hydroxyl group (entry 4), the reduction yielded lactam 11d as the major product (trans/cis $=75 / 25$ ). These stereochemical outcomes can be rationalized by the chelation effect of the

Table 1. The stereochemical outcome of the reduction of lactam carbinols 10a-d

\begin{tabular}{|c|c|c|c|c|}
\hline Entry & Substrate & Method $^{\mathrm{a}}$ & Products $\left(\right.$ trans/cis) ${ }^{\mathrm{b}}$ & $\begin{array}{l}\text { Yields } \\
(\%)\end{array}$ \\
\hline 1 & $10 \mathrm{a}$ & A & $11 \mathrm{a}^{\mathrm{c}}$ & 96 \\
\hline 2 & $10 b \mathrm{R}=\mathrm{Ac}$ & A & $11 b^{\mathrm{c}}$ & 17 \\
\hline 3 & $10 \mathrm{c} R=\mathrm{Bn}$ & A & $11 c^{c}$ & 51 \\
\hline 4 & 10d $\mathrm{R}=\mathrm{TBDPS}$ & $\mathrm{A}$ & $\mathbf{1 1 d}+c i s$-isomer $(75 / 25)$ & $68^{\mathrm{d}}$ \\
\hline 5 & $10 \mathbf{a}$ & B & $\mathbf{1 1 a}+c i s$-isomer $(40 / 60)$ & $70^{\mathrm{d}}$ \\
\hline 6 & $10 \mathrm{~b}$ & $\mathrm{~B}$ & $\mathbf{1 1 b}+c i s$-isomer $(43 / 57)$ & $72^{\mathrm{d}}$ \\
\hline 7 & $10 \mathrm{c}$ & $\mathrm{B}$ & $11 \mathbf{c}+c i s$-isomer $(40 / 60)$ & $73^{\mathrm{d}}$ \\
\hline 8 & 10d & $\mathrm{B}$ & $\mathbf{1 1 d}+c i s$-isomer $(60 / 40)$ & $40^{\mathrm{d}}$ \\
\hline
\end{tabular}

${ }^{\text {a }}$ Method $\mathrm{A}$ : $\mathrm{Et}_{3} \mathrm{SiH}, \mathrm{BF}_{3} \cdot \mathrm{OEt}_{2}, \mathrm{CH}_{2} \mathrm{Cl}_{2},-72$ to $0{ }^{\circ} \mathrm{C}$; Method $\mathrm{B}$ : $\mathrm{NaBH}_{3} \mathrm{CN}, \mathrm{HOAc}$, rt.

${ }^{\mathrm{b}}$ The stereochemistry was determined by NOE experiments.

${ }^{\mathrm{c}}$ Only observed the trans-isomer.

${ }^{\mathrm{d}}$ The two isomers can be separated easily by silica gel column chromatography. The yields are combined isolation yields.
C-4 oxygen substituent that directs the triethylsilane to attack the acylimminium ion intermediate from the same side. ${ }^{8 a, 9}$ The stereoselectivity was converted into slight preference of the cis-isomer (entries 5-7) when using sodium cyanoborohydride in acetic acid. However, the reduction of carbinol 10d (entry 8) under this condition still gave 11d as the major product.

With lactam 11a in hand, the hydoxyl group was then protected as acetate by the reaction with acetic anhydride to afford $\mathbf{1 1 b}(92 \%)$. Treatment of $\mathbf{1 1 b}$ with NCS in carbon tetrachloride gave $\alpha$-chloro sulfide ${ }^{10} \mathbf{1 2}$ that was directly oxidized with MCPBA without purification to obtain $\alpha$-chloro sulfone $7(86 \%)$. The reaction of 7 with excess tributyltin hydride (3 equiv) afforded bicyclic lactam $13(81 \%)$ as a mixture of two isomers epimeric at the exo-cyclic chiral center. ${ }^{3,11-14}$

The final stage of the synthesis requires the conversion of the allyl moiety to an allylic alcohol. This was accomplished by the reaction of bicyclic lactam 13 with 2 equiv of phenylslenenyl bromide in acetonitrile to obtain bromide $\mathbf{1 4}$ in $90 \%$ yield. $^{3}$ This process involved the formation of selenide $\mathbf{1 6}$ that further reacted with phenylslenenyl bromide to give bromide 14. Note that a large excess of lithium bromide ( 8 equiv) was added to facilitate the reaction. Without the addition of lithium bromide the initial formation of selenide $\mathbf{1 6}$ was always contaminated with allyl bromide 17. Bromide 14 was displaced with potassium acetate in the presence of 18-crown-6. The silyl group was also removed in the same step when a small amount of water was present. This led to the formation of diacetate $\mathbf{1 5}^{15,16}$ in $58 \%$ yield. The conversion of diacetate $\mathbf{1 5}$ to (+)-heliotridine (4) has been reported by Dener and Hart. ${ }^{16 a}$

As mentioned above, sodium cyanoborohydride reduction of lactam diol 10a in acetic acid (Table 1, entry 5) afforded the cis-isomer of lactam 11a as the major product. However, the stereoselectivity of this reduction is not satisfactory for the synthesis of (-)-retronecine (5). We decided to employ the methodology reported by Vasella and Bürli17 to intramolecularly deliver the trimethylsilylacetylene group with the help of the adjacent hydroxyl group. In this direction (Scheme 4), we started from imide 9 and regioselectively reduced the carbonyl group adjacent to the hydroxyl group using sodium borohydride under the condition reported by Speckamp. ${ }^{18}$ The resulting crude $\alpha$-acylamino alcohol was converted directly to the methyl ether $18(95 \%)$ in methanol with catalytic amount of $p$-toluenesulfonic acid.

The methyl ether $\mathbf{1 8}$ was first silylated with diethyl trimethylsilylethynyl chloro silane ${ }^{17}$ in the presence of triethylamine and catalytic amount of 4-DMAP in dichloromethane. The reaction mixture was then cooled to $-78^{\circ} \mathrm{C}$ followed by the addition of excess titanium tetrachloride ( 3.7 equiv). This one pot process successfully gave the lactam alcohol 19 with a cis-relationship of the hydroxyl and acetylenic groups. This reaction involved the formation of silyl ether $\mathbf{2 3}$ (Scheme 5) first. The addition of titanium tetrachloride to the solution of 


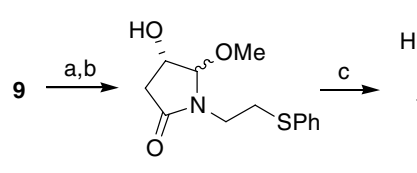

18

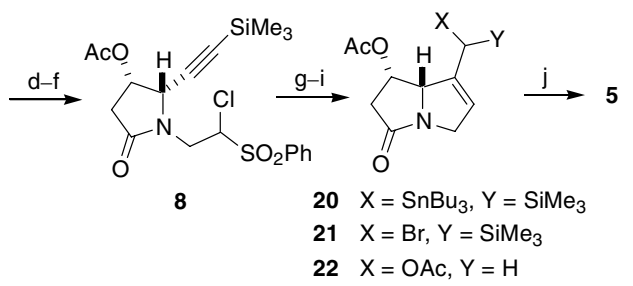

Scheme 4. Reagents and conditions: (a) $\mathrm{NaBH}_{4}, 0^{\circ} \mathrm{C}$, THF/EtOH; (b) p-TsOH, $\mathrm{MeOH}, 95 \%$; (c) $\mathrm{ClEt}_{2} \mathrm{Si}\left(\mathrm{CCSiMe}_{3}\right)$ (1.5 equiv), $\mathrm{Et}_{3} \mathrm{~N}$ (1.5 equiv), 4-DMAP (cat.), $\mathrm{CH}_{2} \mathrm{Cl}_{2}, \mathrm{rt}, \mathrm{TiCl}_{4}\left(3.7\right.$ equiv), $-78^{\circ} \mathrm{C}, 80 \%$; (d) $\mathrm{Ac}_{2} \mathrm{O}$, 4-DMAP (cat.), $\mathrm{Et}_{3} \mathrm{~N}, \mathrm{CH}_{2} \mathrm{Cl}_{2}$; (e) $\mathrm{NCS}, \mathrm{CCl}_{4}$; (f) $\mathrm{MCPBA}$, $\mathrm{CH}_{2} \mathrm{Cl}_{2}, 85 \%$; (g) $\mathrm{Bu}_{3} \mathrm{SnH}$ (2.5 equiv), AIBN (0.1 equiv), $\mathrm{C}_{6} \mathrm{H}_{6}, 80{ }^{\circ} \mathrm{C}$, $58 \%$ of 20; (h) $\mathrm{PhSeBr}$ (2 equiv), $\mathrm{LiBr}$ (8 equiv), $\mathrm{CH}_{3} \mathrm{CN},-40{ }^{\circ} \mathrm{C}$ to $\mathrm{rt}$, $97 \%$ of 21; (i) KOAc, 18-crown-6, $\mathrm{H}_{2} \mathrm{O}, \mathrm{CH}_{3} \mathrm{CN}, \mathrm{rt}, 84 \%$ of 22; (j) LAH, THF, $\Delta, 63 \%$.

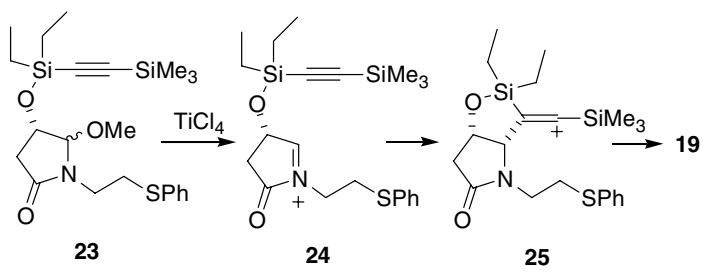

Scheme 5.

23 generated the acyliminium ion $\mathbf{2 4}$ that cyclized to form the vinyl cation intermediate 25. Desilylation of 25 regenerated the acetylenic group at the same side of the transporting oxygen atom.

The rest of the synthesis was carried out in a similar fashion as in the case of (+)-heliotridine (4). Thus, as shown in Scheme 4, acetylation of lactam 19 followed by chlorination and oxidation afforded $\alpha$-chloro sulfone $\mathbf{8}$ in an $85 \%$ overall yield. Radical cyclization of 8 provided bicyclic lactam 20 (58\%). The bicyclic lactam 20 was then converted to allyl bromide 21 (97\%). Substitution of bromide $\mathbf{2 1}$ with potassium acetate gave the desilylated diacetate $\mathbf{2 2}^{19}$ (84\%). Finally, lithium aluminum hydride reduction of $\mathbf{2 2}$ produced (-)-retronecine $(5)^{20-22}$ in $63 \%$ yield.

In summary, starting from (-)-malic acid derived imide 6 we were able to synthesize either $(+)$-heliotridine (4) or (-)-retronecine (5) with high stereoselectivity. Relying on the pre-existing stereogenic center in imide $\mathbf{6}$, we could control the stereochemistry of the newly formed adjacent chiral center at will. The B-ring of the target alkaloids was formed through a key radical cyclization step involving $\alpha$-sulfonyl radical. The synthetic approach developed here has the potential to be extended to the synthesis of the more functionalized alkaloids of the same family.

\section{Acknowledgements}

Financial support by the National Science Council of the Republic of China is gratefully acknowledged.

\section{References and notes}

1. Mattocks, A. R. Chemistry and Toxicology of Pyrrolizidine Alkaloids; Academic: New York, 1986.

2. Liddell, J. R. Nat. Prod. Rep. 2002, 19, 773-781.

3. Tsai, Y.-M.; Ke, B.-W.; Yang, C.-T.; Lin, C.-H. Tetrahedron Lett. 1992, 33, 7895-7898.

4. For recent reviews about radical cyclizations in alkaloid synthesis: (a) Hart, D. J. In Radicals in Organic Synthesis; Renaud, P., Sibi, M. P., Eds.; Wiley-VCH: New York, 2001; vol. 2, pp 279-302; (b) Bowman, W. R.; Fletcher, A. J.; Potts, G. B. S. J. Chem. Soc., Perkin Trans. 1 2002, 2747-2762.

5. (a) Chamberlin, A. R.; Chung, J. Y. J. Am. Chem. Soc. 1983, 105, 3653-3656; (b) Choi, J.-K.; Hart, D. J. Tetrahedron 1985, 41, 3959-3971.

6. For the utilization of malic acid in the asymmetric synthesis of pyrrolizidines, see: Dai, W.-M.; Nagao, Y.; Fujita, E. Heterocycles 1990, 30, 1231-1261, and references cited therein.

7. (a) Mitsunobu, O. Synthesis 1981, 1-28; (b) Hughes, D. L. Org. React. 1992, 42, 335-656.

8. (a) Huang, P. Q.; Wang, S. L.; Ye, J. L.; Ruan, Y. P.; Huang, Y. Q.; Zheng, H.; Gao, J. X. Tetrahedron 1998, 54, 12547-12560; (b) Yoda, H.; Kitayama, H.; Yamada, W.; Katagiri, T.; Takabe, K. Tetrahedron: Asymmetry 1993, 4, 1451-1454.

9. For alternative explanations, see: (a) Cieplak, A. S. Chem. Rev. 1999, 99, 1265-1336; (b) Ohwada, T. Chem. Rev. 1999, 99, 1337-1375.

10. Dilworth, B. M.; McKervey, M. A. Tetrahedron 1986, 42, 3731-3752.

11. Ke, B.-W.; Liu, C.-H.; Tsai, Y.-M. Tetrahedron 1997, 53, 7805-7826.

12. Clive, D. L. J.; Boivin, T. L. B.; Angoh, A. G. J. Org. Chem. 1987, 52, 4943-4953.

13. Paquette, L. A. Synlett 2001, 1-12.

14. Ueno, Y.; Aoki, S.; Okawara, M. J. Am. Chem. Soc. 1979, 101, 5414-5415.

15. The spectroscopic data of this material is identical to that reported in the literature (Ref. 5,16). $[\alpha]_{\mathrm{D}}^{22.8}+34.7(c, 0.92$ in $\left.\mathrm{CHCl}_{3}\right)\left[\right.$ lit. ${ }^{16 \mathrm{~b}}[\alpha]_{\mathrm{D}}^{25}+34.4\left(c, 2.2\right.$ in $\left.\left.\mathrm{CHCl}_{3}\right)\right]$.

16. (a) Dener, J. M.; Hart, D. J. Tetrahedron 1988, 44, 70377046; (b) Kametani, T.; Yukawa, H.; Honda, T. J. Chem. Soc., Perkin Trans. 1 1990, 571-577.

17. Bürli, R.; Vasella, A. Helv. Chim. Acta. Acta 1996, 79, 1159-1168.

18. Hubert, J. C.; Wijnberg, J. B. P. A.; Speckamp, W. N. Tetrahedron 1975, 31, 1437-1441.

19. Characterization of 22: $[\alpha]_{\mathrm{D}}^{26}+67.2\left(c, 1.11\right.$ in $\left.\mathrm{CHCl}_{3}\right)$; IR $\left(\mathrm{CH}_{2} \mathrm{Cl}_{2}\right) 1746(\mathrm{C}=\mathrm{O}), 1709(\mathrm{C}=\mathrm{O}) \mathrm{cm}^{-1} ;{ }^{1} \mathrm{H}$ NMR $\left(\mathrm{CDCl}_{3}, 400 \mathrm{MHz}\right) \delta 2.01\left(\mathrm{~s}, 3 \mathrm{H}, \mathrm{COCH}_{3}\right), 2.06(\mathrm{~s}, 3 \mathrm{H}$, $\left.\mathrm{COCH}_{3}\right), 2.38\left(\mathrm{~d}, J=17.2 \mathrm{~Hz}, 1 \mathrm{H}, \mathrm{COCH}_{2}\right), 2.98(\mathrm{dd}$, $\left.J=17.2,4.8 \mathrm{~Hz}, 1 \mathrm{H}, \mathrm{COCH}_{2}\right), 3.77$ (br d, $J=17.0 \mathrm{~Hz}$, $\left.1 \mathrm{H}, \mathrm{NCH}_{2}\right), 4.43$ (br d, $\left.J=17.0 \mathrm{~Hz}, 1 \mathrm{H}, \mathrm{NCH}_{2}\right), 4.60$ (d of $\left.\mathrm{AB}, J=12.8 \mathrm{~Hz}, 1 \mathrm{H}, \mathrm{OCH}_{2}\right), 4.69(\mathrm{~d}$ of $\mathrm{AB}$, $\left.J=12.8 \mathrm{~Hz}, 1 \mathrm{H}, \mathrm{OCH}_{2}\right), 4.84($ br s, $1 \mathrm{H}, \mathrm{NCH}), 5.52(\mathrm{t}$, $J=4.0 \mathrm{~Hz}, 1 \mathrm{H}, \mathrm{OCH}), 5.88($ br s, $1 \mathrm{H},=\mathrm{CH}) ;{ }^{13} \mathrm{C} \mathrm{NMR}$ $\left(\mathrm{CDCl}_{3}, 100 \mathrm{MHz}\right) \delta 20.7(\mathrm{q}), 21.0(\mathrm{q}), 41.9(\mathrm{t}), 49.7(\mathrm{t})$, $60.2(\mathrm{t}), 71.0$ (d), 72.5 (d), 127.4 (d), 134.3 (s), 170.0 (s), $170.5(\mathrm{~s}), 175.1$ (s); HRMS calcd for $\mathrm{C}_{12} \mathrm{H}_{15} \mathrm{NO}_{5} \mathrm{~m} / \mathrm{z}$ 253.0945, found $\mathrm{m} / \mathrm{z} 253.0948$. 
20. The spectroscopic data of this material is identical to that reported in the literature (Ref. 21$) \cdot[\alpha]_{\mathrm{D}}^{23.1}-53.2(c, 1.15$ in EtOH) $\left[\right.$ lit. $\left.^{22}[\alpha]_{\mathrm{D}}^{20}-52.9(\mathrm{EtOH})\right]$.

21. (a) Niwa, H.; Miyachi, Y.; Okamoto, O.; Uosaki, Y.; Kuroda, A.; Ishiwata, H.; Yamada, K. Tetrahedron 1992,
48, 393-412; (b) Drewes, S. E.; Antonowitz, I.; Kaye, P. T.; Coleman, P. C. J. Chem. Soc., Perkin Trans. 1 1981, 287-289.

22. Nishimura, Y.; Kondo, S.; Umezawa, H. J. Org. Chem. 1985, 50, 5210-5214. 